\title{
Routine appendicectomy be performed as a part of surgical staging in ovarian cancer
}

\author{
Shveta Giri ${ }^{1}$, Pavika Lal $^{2}$, Sudhir Rawal ${ }^{1}$, Rupinder Sekhon ${ }^{1}$
}

\author{
${ }^{1}$ Department of Urogynaeoncology, RGCI and RC Rohini, New Delhi, India \\ ${ }^{2}$ Department of Obstetrics and Gynaecology, G.S.V.M. Medical College, Kanpur, Uttar Pradesh, India
}

Received: 12 September 2016

Accepted: 07 October 2016

\author{
*Correspondence: \\ Dr. Shveta Giri, \\ E-mail: drshvetagiri@yahoo.co.in
}

Copyright: ( ) the author(s), publisher and licensee Medip Academy. This is an open-access article distributed under the terms of the Creative Commons Attribution Non-Commercial License, which permits unrestricted non-commercial use, distribution, and reproduction in any medium, provided the original work is properly cited.

\begin{abstract}
Background: The role of appendicectomy in epithelial ovarian malignancy is debatable, and therefore to incorporate appendicectomy as a part of surgical staging especially in nonmucinous epithelial types of ovarian cancer is a real subject of controversy. The aim was to determine the incidence of appendiceal involvement in ovarian malignancy and the factors which increase the probability of involvement.

Methods: This was a retrospective study conducted at gynecology department at RGCI and RC, New Delhi. 102 women who had undergone staging laparotomy for ovarian malignancy in whom routine appendectomy was also done between January 2011 and April 2014 were included. Demographic data along with tumor markers and detailed histopathological findings were recorded and statistical analysis using multiple logistic regression curves was done.

Results: Out of 102 women, appendiceal involvement was identified in 52 (50.98\%). Patients in whom omentum and lymphnode were positive for metastasis (O.R: 13.7, P: 0.002; O.R: 6.6, P: 0.002; respectively) showed significantly higher chance of involvement of appendix. Though statistically not significant, women having right or bilateral tumors, Ca 125 value $>500 \mathrm{u} / \mathrm{ml}$ and positive peritoneal cytology also had higher chances of appendiceal metastasis.

Conclusions: This study showed that there was higher incidence of appendiceal metastasis in advanced stages (III and IV). Thus appendicectomy can be incorporated routinely in the surgical management (mucinous /non mucinous) even if there is no gross involvement to achieve optimal debulking.
\end{abstract}

Keywords: Appendicectomy, Ovarian malignancy, Risk factors, Surgical staging

\section{INTRODUCTION}

Ovarian malignancy is one of the gynaecological malignancies with highest case to fatality ratio. The best treatment is staging laparotomy with primary debulking with minimal or no residual disease followed by adjuvant chemotherapy. The appendix is an intraperitoneal organ in $95 \%$ of the cases and prone to metastatic involvement by epithelial ovarian cancers. ${ }^{1}$ This study was done with the aim to analyze the importance of appendicectomy in patients with epithelial ovarian cancer and to demonstrate the possible relationship with clinico-pathologic variables.

\section{METHODS}

This was a retrospective study conducted from Jan 2011 to April 2014. Women who underwent primary as well as interval cytoreductive surgery for ovarian cancer in which appendicectomy was performed were enrolled in this study. Patients who did not have appendicectomy for other reasons (prior appendicectomy, personal preference of the surgeons) and the patients with incomplete clinicopathologic data were all excluded from the study. Those women who had undergone secondary cytoreductive and completion surgery were excluded from our study. All patients were subjected to initial surgical staging procedure according to the 
recommendations of the International federation of gynecology and obstetrics. Demographic data, age, parity, body surface area, tumor markers: Ca 125, CEA, Ca-19.9 and detailed histopathological findings were recorded and analysed from medical records.

Statistical analysis: All the data were analyzed with Epiinfo and SP SS software. Quantitative variables were summarized by means and SD variables, following non normal distribution. Categorical variables were summarized by frequencies $(\%)$ and were compared with Pearson Chi- Sq test or fisher - exact test. The Odd Ratio and their correspondence $95 \%$ Confidence interval was calculated using unconditional multiple logistic regression analysis.

\section{RESULTS}

Demographic information, potential risk factors and surgical indications were recorded.

Table 1: Incidence of appendiceal metastasis in various stages of ovarian cancer.

\begin{tabular}{|lll|}
\hline Stage & $\mathbf{N}=102$ & A ppendiceal metastasis \\
\hline I & $13(12.87 \%)$ & 0 \\
\hline II & $7(6.93 \%)$ & 0 \\
\hline III & $80(78.43 \%)$ & 51 \\
\hline IV & $2(1.98 \%)$ & 1 \\
\hline
\end{tabular}

Table 2: Demographic / clinical /biochemical characteristics of study population with and without appendiceal metastasis.

\begin{tabular}{|lll|l|}
\hline & $\begin{array}{l}\text { Appendix } \\
\text { positive } \\
(\mathrm{N}=52)\end{array}$ & $\begin{array}{l}\text { Appendix } \\
\text { negative } \\
(\mathrm{N}=50)\end{array}$ & $\begin{array}{l}\text { p- } \\
\text { value }\end{array}$ \\
\hline Mean Age & $53.4 \pm 10.4$ & $51.6 \pm 12.2$ & 0.4 \\
\hline Mean Parity & $2.6 \pm 1.6$ & $2.5 \pm 12.2$ & 0.4 \\
\hline Mean BSA & $1.5 \pm 0.1$ & $1.6 \pm 0.1$ & 0.1 \\
\hline $\begin{array}{l}\text { Median preop } \\
\text { CA 125 (U/ml) }\end{array}$ & $\begin{array}{l}1303(47.8- \\
12900)\end{array}$ & $\begin{array}{l}724(9.7- \\
21300)\end{array}$ & 0.01 \\
\hline Median CEA & $\begin{array}{l}1.2(0.3- \\
25.1)\end{array}$ & $\begin{array}{l}1.7(0.3- \\
3420)\end{array}$ & 0.08 \\
\hline $\begin{array}{l}\text { Median CA } \\
\text { 19.9 }\end{array}$ & $\begin{array}{l}8.5(1.4- \\
904)\end{array}$ & $\begin{array}{l}10.15(0.6- \\
52900)\end{array}$ & 0.2 \\
\hline $\begin{array}{l}\text { Max. diameter } \\
\text { of tumor }(\mathrm{cm})\end{array}$ & $7.1 \pm 4.7$ & $11.5 \pm 7.6$ & 0.008 \\
\hline
\end{tabular}

A total number of 102 women who had undergone staging laparotomy for ovarian malignancy in whom appendicectomy was also done were included during this study period. Incidence of appendiceal metastasis was seen in 52 cases $(50.98 \%)$. Maximum numbers of patients were in stage III $(78.43 \%)$ and among whom appendical involvement was seen in 51.The mean age of our study population was $52.55 \pm 1.33$ which was comparable among two groups (Appendix positive/appendix negative). The main histopathological type in our study was serous (77.45) and other types of histopathology with metastasis to appendix was shown in table 3.Multiple logistic regression analysis of risk factors showed significantly higher chance of involvement of appendix in whom omentum and, lymphnode were positive for malignancy (O.R: 13.7, P: 0.002; O.R: 6.6, P: 0.002; respectively). Though statistically not significant, women having right or bilateral tumors, $\mathrm{Ca} 125$ value $>500 \mathrm{u} / \mathrm{ml}$ and positive peritoneal cytology also had higher chance of appendiceal metastasis (Table 4). No significant association was seen with mean CA 19.9 and carcinoembryonic antigen.

\section{Table 3: Different histological type of ovarian} malignancy with appendiceal metastasis.

\begin{tabular}{|lll|}
\hline Histological type & $\mathrm{N}=102$ & $\begin{array}{l}\text { Appendiceal } \\
\text { metastasis }(\mathrm{N}=52)\end{array}$ \\
\hline Epithelial & $94(92.16 \%)$ & 50 \\
\hline Serous & $79(76.3 \%)$ & 48 \\
\hline Mucinous & $3(2.94 \%)$ & 0 \\
\hline Borderline serous & $2(1.96 \%)$ & 0 \\
\hline $\begin{array}{l}\text { Borderline } \\
\text { mucinous }\end{array}$ & $4(3.92 \%)$ & 0 \\
\hline Other & $6(5.88 \%)$ & 2 \\
\hline Non epithelial & $8(7.84 \%)$ & 2 \\
\hline
\end{tabular}

Table 4: Predictors of appendiceal metastasis (multiple logistic regression analysis).

\begin{tabular}{|lll|}
\hline Predictors & OR $(95 \%$ CI $)$ & P-value \\
\hline Omentum positive & 13.7 & 0.002 \\
\hline $\begin{array}{l}\text { Pelvic lymph nodes } \\
\text { positive }\end{array}$ & 6.6 & 0.002 \\
\hline Peritoneal fluid positive & 3.17 & 1.0 \\
\hline Right/ bilateral & 1.9 & 0.5 \\
\hline $\begin{array}{l}\text { Maximum tumor } \\
\text { diameter }>10 \mathrm{~cm}\end{array}$ & 0.15 & 0.01 \\
\hline Preop CA-125 $>500 \mathrm{U} / \mathrm{ml}$ & 1.01 & 0.9 \\
\hline
\end{tabular}

\section{DISCUSSION}

Comprehensive surgical staging and the optimal or maximal cytoreduction are the most important objectives of treatment in epithelial ovarian carcinoma. Ovarian cancer has a well-established widespread peritoneal dissemination. $^{2-4}$ Although the surface of the appendix constitutes less than $1 \%$ of the peritoneal cavity, it is suggested as a frequent metastatic site. In our study, the overall incidence of metastasis to appendix in ovarian cancer was 50.98\%. Maximum number $60.7 \%$ (48/79) of appendiceal metastasis was seen in serous adenocarcinoma. This may be due to the high prevalence of serous histology in our study. All appendiceal metastasis in our study were seen in advanced cases (stage III and IV) of ovarian cancer. None of early case of ovarian cancer (stage I and II) shows metastasis to appendix. This was in accordance with the studies conducted by Rose et al, Malfetano and Takac who 
reported similar high rates in stage III-IV disease $(69.7 \%$, $69-75 \%$ and $54.2 \%$ respectively). ${ }^{1,5}$ Ayhan et al concluded that routine appendectomy is indicated in all cases of epithelial ovarian malignancy as part of the initial surgical staging procedure because of considerable rate of upstaging in early stage disease and optimal cyto reduction in advanced stages.

Our study shows significantly higher chance of involvement of appendix in whom omentum, lymphnode were positive for malignancy (O.R: 13.7, P: 0.002; O.R: 6.6 , P: 0.002 ; respectively). Though statistically not significant, women having right or bilateral tumors, CA 125 value $>500 \mathrm{u} / \mathrm{ml}$ and positive peritoneal cytology also had higher chance of appendiceal metastasis. Chae Hyeong et al shows no significant relationship between appendiceal metastases and preoperative CA 125 level. $^{8}$ On the contrary Ayhan et al found that pre operative CA $125>500 \mathrm{u} / \mathrm{ml}$ was found to be significantly related to appendiceal metastases. ${ }^{7}$ In our study, maximum tumor diameter $>10 \mathrm{cms}$ was not found to be a significant factor determining the appendiceal metastasis. This was because bigger tumor size in our study was mostly seen in borderline tumors and was in early stages. A similar finding was also reported by Chae Hyeong et al. ${ }^{8}$ On the contrary, Ayhan et al reported that maximum diameter of tumor $>10 \mathrm{~cm}$ was a significant risk factor. ${ }^{7}$ Similar to our study Fontanelli reported a higher prevalence appendiceal involvement in patients with right sided tumor. ${ }^{9}$ The reason behind this is due to close proximity of the tumors to the appendix.

The limitation of our study is that it was a retrospective study and segregation of gross and microscopic metastasis to appendix was not done. Also there were only limited cases of early stages of ovarian malignancy where appendectomy was done, thus it was difficult to draw conclusion that routine appedicectomy should be a part of comprehensive surgical staging in early stage. So for this, there is a need of prospective randomized controlled trial.

\section{CONCLUSION}

The study showed that appendicectomy should be a part of cytoreductive surgery even in non mucinous ovarian cancer especially when omentum and lymphnodes are involved or in advanced stages as routinely appendicectomy only slightly increases the operating time but at the same time might improve the survival without significantly increasing the morbidity of the patient.

\section{ACKNOWLEDGEMENT}

I acknowledge all my contributing authors for their guidance as well as their technical assistance. We all thank to our patients for giving consent for participation in this study.

Funding: No funding sources Conflict of interest: None declared

Ethical approval: The study was approved by the Institutional Ethics Committee

\section{REFERENCES}

1. Malfetano JH. The appendix and its metastatic potential in epithelial ovarian cancer. Obstet Gynecol. 1987;69:396-8.

2. Soper JT. Management of early stage epithelial ovarian cancer. Clin Obstet Gynecol. 1994;37:42338.

3. Leblanc E, Querleu D, Narducci F, Chauvet MP, Chevalier A, Lesoin A. Surgical staging of early invasive epithelial ovarian tumors. Semin Surg Oncol. 2000;19:36-41.

4. Randall TC, Rubin SC. Surgical management of ovarian cancer.Semin Surg Oncol. 1999;17:173-80.

5. Rose PG, Reale FR, Fisher A, Hunter RE. Appendectomy in primary and secondary staging operations for ovarian malignancy. Obstet Gynecol. 1991;77:116-8.

6. Takac I. Role of appendectomy in predicting lymph node metastases in patients with ovarian cancer. Eur J Obstet Gynecol Reprod Biol. 2000;88:159-63.

7. Ayhan A, Gultekin M, Taskiran C. Routine appendectomy in epithelial ovarian carcinoma: is it necessary? Obstet Gynecol. 2005;105:719-24.

8. Hyeong CL, Mi-Kyung K, Ju-Won R, Jae Weon K, Noh-Hyun P, Eung Gi M. Appendectomy for patients presenting with epithelial ovarian cancer apparently confined to the pelvis: To do or not to do? J Womens Med. 2010;3:3-6.

9. Fontanelli R, Paladini D, Raspagliesi F, DiRe E. The role of appendectomy in surgical procedures for ovarian cancer. Gynecol Oncol. 1992;46:42-4.

Cite this article as: Giri S, Lal P, Rawal S, Sekhon

$\mathrm{R}$. Routine appendicectomy be performed as a part of surgical staging in ovarian cancer. Int J Reprod Contracept Obstet Gynecol 2016;5:4263-5. 